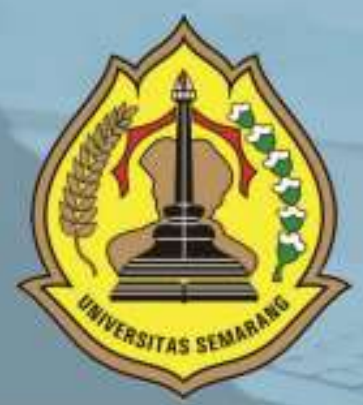

PENGARUH WORK FAMILY CONFLICT, STRES KERJA DAN KEPEMIMPINAN TERHADAP TURNOVER INTENTION KARYAWAN (STUDI PADA SELURUH KARYAWAN BAGIAN PLANNING PRODUCTION AND INVENTORY CONTROL PT. PARKLAND WORLD INDONESIA JEPARA

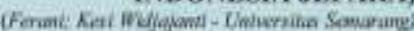

STUDI SOFT SKILL LULUSAN PENDIDIKAN KEJURUAN DI TEMPAT KERJA

Whort-Chiversikio Semorang

ANALISIS IINGKUNGAN INTERNAL DAN EKSTERNAL, PADA UKM PREMIUM PLUS LAUNDRY CABANG MULAWARMAN SEMARANG

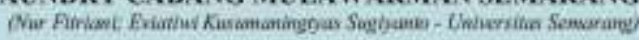

FAKTOR-FAKTOR YANG MEMPENGARUHI PERTIMBANGAN TINGKAT MATERIALITAS AUDIT

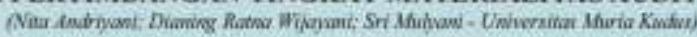

MANAJEMEN LABA DAN FAKTOR-FAKTOR YANG MEMPENGARUHINYA (STUDI EMPIRIS PADA PERUSAHAN MANUFAKTUR DI BEI)

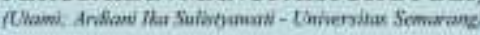

PENDAPATAN ASLI DAERAH, DANA PERIMBANGAN, DAN SISA LEBIH PEMBIAYAAN ANGGARAN TERHADAP PENGALOKASIAN BELANJA MODAL: STUDI PADA KABUPATEN/KOTA DI PROVINSI JAWA TENGAH

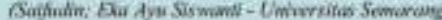

PERSEPSI PENGGUNA JASA TRANS JATENG TERHADAP KUALITAS PELAYANAN ANGKUTAN AGLOMERASI PERKOTAAN TRANS

JATENG

(Studi Kasus Trans Jateng Koridor I Semarang (Tawang) - Bawen)

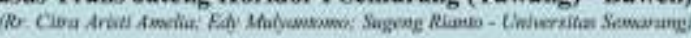

WORTHLESSNESS IS A POWER: MENGAPA ORANG BERSEDIA MENARUH UANG DI APLIKASI GO-PAY

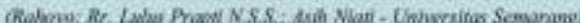

ANALISIS PENGARUH KUALITAS PRODUK, PERSEPSI HARGA, DAN PROMOSI TERHADAP KEPUTUSAN PEMBEIIAN WELLBLUE AL KALINE WATER PITCHER

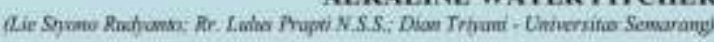

STRATEGI PEMASARAN UNTUK MENINGKATKAN VOLUME PENJUALAN (STUDI KASUS PADA SHOFA CATERING)

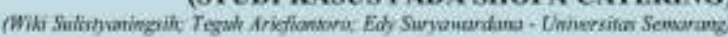

PENGARUH CITRA MEREK, PERSEPSI HARGA, DAN KUALITAS PRODUK TERHADAP KEPUTUSAN PEMBELIAN SEPATU OLAH RAGA MEREK ADIDAS

(Studi di Kota Semarang)

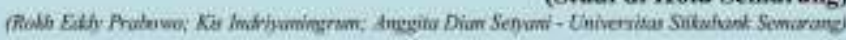

PENGARUH KEMUDAHAN TERHADAP KEPUTUSAN MENGGUNAKAN E-BANKING PADA BNI 46 KC KARANGAYU SEMARANG DENGAN MINAT NASABAH DAN KEPERCAYAAN SEBAGAI VARIABEL. MEDIASI

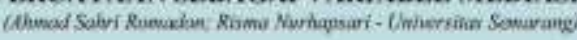

PENELITLAN KEBERLANGSUNGAN USAHA ARDANI INDONESIA SEBAGAI UMKM BERBASIS INDUSTRI KREATIF

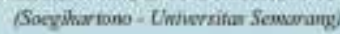

STRATEGI PELAYANAN BUS RAPID TRANSIT (BRT) TRANS SEMARANG

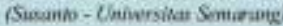

ANALISIS PENGARUH KEPEMIMPINAN, STRES KERJA, DAN LINGKUNGAN KERJA TERHADAP KINERJA KARYAWAN BAGIAN PRODUKSI SEWING PT. SAMWON BUSANA INDONESIA SEMARANG

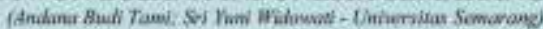




\section{DESKRIPSI}

Majalah IImiah Solusi Mengkaji

Masalah-Masalah Sosial,

Ekonomi dan Bisnis

\section{KETERANGAN TERBIT}

Terbit Pertama Kali Juli 2002

dan SelanjutnyaTerbit Tiga Bulan

Sekali (Januari, April, Juli dan

Oktober)

\section{PENERBIT}

Fakultas Ekonomi USM

\section{ALAMAT PENERBIT}

JL. Soekarno Hatta Semarang

Telp. 024-6702757 Fax. 024-6702272

\section{PENGELOLA}

Editor in Chief : Yohanes Suhardjo, SE, M.Si., Ak, CA Vice Editor Chief : Sugeng Rianto, SE, MM

Managing Editor: Edy Suryawardana, SE, MM

Secretary of Managing Editor : Asih Niati, SE, MM

Administration \& Circulation :

Citra Rizkiana, SE, MM

Layout \& Typesetting : M Burhan Hanif S.Kom, M.Kom

Board of Editors:

1. Prof. Dr. Ir. Kesi Widjajanti, SE, MM (USM)

2. Prof. Drs. Mohammad Nasir, Msi, Ph.D, AK. (USM)

3. Prof. Supramono SE, MBA, DBA (UKSW)

4. Prof. Drs. H. Imam Ghozali, M.Com, Akt, PhD (UNDIP)

5. Prof. Dr. Agus Suroso, MS (UNSOED)

6. Prof. Dr. Widodo, SE, M.Si (UNISSULA)

7. Prof. Dr. Dra. Sulastri, ME, M.Kom (UNSRI)

8. Dr. Ardiani Ika S, SE, MM, Ak, CA, CPA (USM)

\section{KATA PENGANTAR}

Sungguh merupakan kebahagiaan tersendiri bagi kami, takala kami dapat hadir rutin setiap tiga bulan sekali untuk saling bertukar pikiran mengenai hal-hal baru dibidang sosial, ekonomi dan bisnis.

Pada kesempatan ini penerbit menyampaikan terima kasih kepada semua pihak yang telah mengirimkan artikel-artikelnya. Penerbit akan membuka kesempatan seluas-luasnya bagi seluruh kalangan akademisi maupun praktisi baik dari dalam maupun luar Universitas Semarang untuk mempublikasikan karya ilmiahnya.

Penerbitan majalah ilmiah "SOLUSI" kali ini menghadirkan 15 (Lima Belas) artikel yang kami anggap layak untuk diterbitkan, dengan harapan dapat menjadi tambahan referensi bagi para pembaca dan menjadi sumbangan pengembangan persemaian khasanah pengetahuan dibidang sosial, ekonomi dan bisnis.

Akhir kata semoga majalah ilmiah "SOLUSI" dapat memberi manfaat yang sebesar-besarnya.

Hormat Kami 


\section{DAFTAR ISI}

PENGARUH WORK FAMILY CONFLICT, STRES KERJA DAN KEPEMIMPINAN TERHADAP TURNOVER INTENTION KARYAWAN (STUDI PADA SELURUH KARYAWAN BAGIAN PLANNING PRODUCTION AND INVENTORY CONTROL PT. PARKLAND WORLD INDONESIA JEPARA)

(Ferani; Kesi Widjajanti - Universitas Semarang)

STUDI SOFT SKILL LULUSAN PENDIDIKAN KEJURUAN DI TEMPAT KERJA

(Albert - Universitas Semarang)...

ANALISIS LINGKUNGAN INTERNAL DAN EKSTERNAL PADA UKM PREMIUM PLUS

LAUNDRY CABANG MULAWARMAN SEMARANG

(Nur Fitriani; Eviatiwi Kusumaningtyas Sugiyanto - Universitas Semarang)

FAKTOR-FAKTOR YANG MEMPENGARUHI PERTIMBANGAN TINGKAT

MATERIALITAS AUDIT

(Nita Andriyani; Dianing Ratna Wijayani; Sri Mulyani - Universitas Muria Kudus).

MANAJEMEN LABA DAN FAKTOR-FAKTOR YANG MEMPENGARUHINYA

(STUDI EMPIRIS PADA PERUSAHAN MANUFAKTUR DI BEI)

(Utami; Ardiani Ika Sulistyawati - Universitas Semarang)

PENDAPATAN ASLI DAERAH, DANA PERIMBANGAN, DAN SISA LEBIH PEMBIAYAAN ANGGARAN TERHADAP PENGALOKASIAN BELANJA MODAL: STUDI PADA

KABUPATEN/KOTA DI PROVINSI JAWA TENGAH

(Saifudin; Eka Ayu Siswanti - Universitas Semarang).

PERSEPSI PENGGUNA JASA TRANS JATENG TERHADAP KUALITAS PELAYANAN ANGKUTAN AGLOMERASI PERKOTAAN TRANS JATENG

(Studi Kasus Trans Jateng Koridor I Semarang (Tawang) - Bawen)

(Rr. Citra Aristi Amelia; Edy Mulyantomo; Sugeng Rianto - Universitas Semarang)

WORTHLESSNESS IS A POWER: MENGAPA ORANG BERSEDIA MENARUH UANG DI APLIKASI GO-PAY

(Rahoyo; Rr. Lulus Prapti N.S.S.; Asih Niati - Universitas Semarang).

ANALISIS PENGARUH KUALITAS PRODUK, PERSEPSI HARGA, DAN PROMOSI TERHADAP KEPUTUSAN PEMBELIAN WELLBLUE ALKALINE WATER PITCHER

STRATEGI PEMASARAN UNTUK MENINGKATKAN VOLUME PENJUALAN (STUDI KASUS PADA SHOFA CATERING)

(Wiki Sulistyaningsih; Teguh Ariefiantoro; Edy Suryawardana - Universitas Semarang)

PENGARUH CITRA MEREK, PERSEPSI HARGA, DAN KUALITAS PRODUK TERHADAP KEPUTUSAN PEMBELIAN SEPATU OLAH RAGA MEREK ADIDAS

(Studi di Kota Semarang)

(Rokh Eddy Prabowo; Kis Indriyaningrum; Anggita Dian Setyani - Universitas Stikubank Semarang) .121

PENGARUH KEMUDAHAN TERHADAP KEPUTUSAN MENGGUNAKAN E-BANKING PADA BNI 46 KC KARANGAYU SEMARANG DENGAN MINAT NASABAH DAN KEPERCAYAAN SEBAGAI VARIABEL MEDIASI

(Ahmad Sahri Romadon; Risma Nurhapsari - Universitas Semarang) 
PENELITIAN KEBERLANGSUNGAN USAHA ARDANI INDONESIA SEBAGAI UMKM BERBASIS INDUSTRI KREATIF

(Soegihartono - Universitas Semarang)

STRATEGI PELAYANAN BUS RAPID TRANSIT (BRT) TRANS SEMARANG

(Susanto - Universitas Semarang).....

ANALISIS PENGARUH KEPEMIMPINAN, STRES KERJA, DAN LINGKUNGAN KERJA TERHADAP KINERJA KARYAWAN BAGIAN PRODUKSI SEWING PT. SAMWON BUSANA INDONESIA SEMARANG

(Andana Budi Tami; Sri Yuni Widowati - Universitas Semarang). 


\title{
ANALISIS PENGARUH KEPEMIMPINAN, STRES KERJA, DAN \\ LINGKUNGAN KERJA TERHADAP KINERJA KARYAWAN BAGIAN \\ PRODUKSI SEWING PT. SAMWON BUSANA INDONESIA SEMARANG
}

\author{
Andana Budi Tami \\ Sri Yuni Widowati \\ Fakultas Ekonomi Universitas Semarang
}

Diterima: Agustus 2020, Disetujui: September 2020, Dipublikasikan: Oktober 2020

\begin{abstract}
This study aims to examine empirically the influence of leadership, work stress and work environment on the performance of employees in sewing production PT. Samwon Busana Indonesia Semarang. The population of this research was 330 sewing production employees at PT. Samwon Busana Indonesia Semarang. The sample used in this study was 77 respondents using purposive sampling technique, which is a sampling technique that provides an opportunity to become a member of the sample with certain criteria. Then the method of data collection through questionnaire and data analysis using SPSS 21 which includes validity, reliability, classical assumption, multiple regression analysis, hypothesis testing using $t$ test, $F$ test, $R 2$ test. The results of this study indicate that all independent variables, namely leadership (X1), work stress (X2), and work environment (X3) have a positive and significant effect on employee performance $(Y)$ partially or stimulently (together). Based on the determination coefficient value of 0.841, it is known that in this study, leadership, work stress and work environment have an influence on employee performance variables of $84.1 \%$ while the rest which is equal to $15.9 \%$ is influenced by other variables.
\end{abstract}

Keywords : Leadership, work stress, work environment and employee performance.

ABSTRAK
Penelitian ini bertujuan untuk menguji secara empiris pengaruh kepemimpinan, stres kerja dan lingkungan kerja terhadap kinerja karyawan bagian produksi sewing PT. Samwon Busana Indonesia Semarang. Populasi penelitian ini sebanyak 330 karyawan produksi bagian sewing PT.Samwon Busana Indonesia Semarang. Sampel yang digunakan dalam penelitian ini adalah 77 orang responden dengan menggunakan teknik purposive sampling, yaitu teknik pengambilan sampel yang memberikan kesempatan menjadi anggota sampel dengan kriteria tertentu. Kemudian metode pengumpulan data melalui kuosioner dan analisa data menggunakan SPSS 21 yang meliputi uji validitas, reliabilitas, uji asumsi klasik, analisis regresi berganda, pengujian hipotesis menggunakan uji t, uji $\mathrm{F}$, uji $\mathrm{R}^{2}$. Hasil penelitian ini menunjukkan bahwa seluruh variabel bebas, yaitu kepemimpinan $\left(\mathrm{X}_{1}\right)$, stres kerja $\left(\mathrm{X}_{2}\right)$, dan 
lingkungan kerja $\left(\mathrm{X}_{3}\right)$ berpengaruh positif dan signifikan terhadap kinerja karyawan (Y) secara parsial maupun stimultan (bersama-sama). Berdasarkan nilai koefisien determinasi sebesar 0,841 diketahui bahwa dalam penelitian ini.kepemimpinan, stres kerja dan lingkungan kerja berpengaruh terhadap variabel kinerja karyawan sebesar $84,1 \%$ sedangkan sisanya yaitu sebesar $15,9 \%$ dipengaruhi oleh variabel lain.

Kata kunci : Kepemimpinan, stres kerja, lingkungan kerja dan kinerja karyawan.

\section{PENDAHULUAN}

Dalam menghadapi era globalisasi dimana terjadi persaingan yang ketat didalam dunia industri garment, setiap perusahaan harus memiliki strategi supaya terus dapat bersaing dengan perusahaan lain. Salah satu strategi perusahaan agar dapat terus bersaing adalah memaksimalkan dan mengoptimalkan sumber daya yang dimiliki perusahaaan tersebut. Oleh sebab itu setiap perusahaan dituntut untuk lebih kreatif dan inovatif dalam suatu hasil produksi, dengan terus berkembangnya dunia mode fashion, begitu pula dengan kualitas sumber daya manusia dalam hal ini yaitu karyawan, merupakan hal yang perlu diperhatikan oleh setiap perusahaan.

Faktor-faktor suatu produksi didalam perusahaan tentunya berpengaruh antar depertemen dalam perusahaaan. Beberapa faktor produksi yang menunjang kegiatan produksi antara lain, adalah : sumber daya manusia (SDM), metode, mesin, bahan baku atau material.

Menurut Hasibuan (2008) Sumber Daya Manusia adalah kemampuan terpadu dari daya pikir dan daya fisik yang dimiliki individu . oleh karena itu , kualitas sumber daya manusia perlu didorong lebih baik lagi agar dapat mencapai tujuan organisasi perusahaan yang efektif dan efisien. Manfaat dari optimalnya sumber daya manusia (SDM) yaitu organisasi mendapat laba, karyawan mendapatkan kepuasan kerja.

Sumber daya manusia (SDM) didalam perusahaan memilki peranan besar, dimana kinerja karyawan sangat menentukan maju mundurnya perusahaan tersebut. Sehingga diperlukan pembinaan dan pelatihan tentang kinerja karyawan yang efektif demi kelancaran kegiatan produksi dalam perusahaan. Oleh karena itu, sudah seharusnya kinerja karyawan perlu diperhatikan secara adil, sehingga karyawan dapat melaksanakan tugasnya dengan maksimal.

Suatu faktor individu yang mendasari sikap dan perilaku seseorang untuk mendorong semangat kerja untuk menyelesaikan suatu tugasnya adalah kedisplinan. Menurut Hasibuan (2012:193), Disiplin kerja adalah kesadaran dan kesediaan seseorang menaati semua peraturan perusahaan dan norma-norma sosial yang berlaku. Dengan semakin tingginya tingkat kedisiplinan yang dimiliki seorang karyawan maka akan menumbuhkan prestasi kerja setiap karyawan serta meningkatkan produktivitas. 
Lingkungan kerja ternyata memiliki pengaruh besar terhadap efektivitas dan efisiensi dalam pelaksanaan tugas. Menurut Soetjipto (2008:87), Lingkungan kerja adalah segala suatu hal atau unsur-unsur yang dapat mempengaruhi secara langsung maupun tidak langsung terhadap organisasi atau perusahaan yang akan memberikan dampak baik ataupun buruk terhadap kinerja karyawan. Lingkungan kerja mendukung akan lebih memudahkan karyawan dalam menjalankan tugas yang dibebankan.

Dalam pemberian tugas kepada karyawan, salah satu faktor yang perlu diperhatikan oleh perusahaan adalah Kepemimpinan yang baik mampu mempengaruhi kinerja karyawan. PT. Samwon Busana Indonesia Semarang merupakan sebuah perusahaan percetakan yang bergerak di bidang offset packaging yang tentunya menggunakan mesin mesin industri yang canggih yang dikendalikan penuh oleh manusia. Perusahaan ini pada dasarnya selalu berusaha untuk mewujudkan harapan agar dapat meningkatkan kinerja karyawan. Hal ini yang melatar belakangi permasalahan bahwa kinerja karyawan bagian produksi tersebut mengalami penurunan. Penururnan pendapatan dapat menjadi salah satu faktor dimana terjadinya penurunan kinerja, oleh karena itu, perusahaan harus mengatur pola kerja karyawan dengan disiplin kerja. Faktor yang menjadi penyebab menurunnya kinerja karyawan yaitu cara kerja karyawan yang tidak teratur. Lingkungan kerja bisa mempengaruhi kinerja karyawan yang meliputi penerangan lampu, suhu udara,dan lain - lain yang mampu meningkatkan suasana kondusif serta pemberian kompensasi yang mampu memberikan semangat kerja para karyawan.

\section{TINJAUAN PUSTAKA}

\section{Kinerja Karyawan}

Menurut Mangkunegara (2009:67), Kinerja adalah hasil kerja secara kualitas dan kuantitas yang dicapai oleh seorang pegawai dalam melaksanakan tugasnya sesuai dengan tanggung jawab yang diberikan kepadanya. Kinerja juga merupakan suatu hasil kerja yang dihasilkan oleh seorang pegawai diartikan untuk mencapai tujuan yang diharapkan.

Menurut Mangkunegara (2009 : 75) mengemukakan bahwa indikator kinerja, yaitu :

1. Kualitas

Kualitas kerja adalah seberapa baik seorang karyawan mengerjakan apa yang seharusnya dikerjakan.

2. Kuantitas

Kuantitas kerja adalah seberapa lama seorang pegawai bekerja dalam satu harinya. Kuantitas kerja ini dapat dilihat dari kecepatan kerja setiap pegawai itu masing-masing.

3. Pelaksanaan tugas

Pelaksanaan Tugas adalah seberapa jauh karyawan mampu melakukan pekerjaannya dengan akurat atau tidak ada kesalahan. 


\section{Tanggung Jawab}

Tanggung jawab terhadap pekerjaan adalah kesadaran akan kewajiban karyawan untuk melaksanakan pekerjaan yang diberikan perusahaan.

\section{Kepemimpinan}

Menurut Hasibuan (dalam Reni Marahi, 2015) mengemukakan bahwa kepemimpinan yang ditetapkan oleh manajer dalam organisasi dapat menciptakan integrasi yang serasi dan mendorong gairah kerja karyawan untuk mencapai sasaran yang maksimal.kepemimpinan mengndung arti cara pemimpin mempengaruhi bawahan untuk lebih dapat berbuat atau berusaha dalam rangka mencapai tujuan organisasi, dengan demikian dari seorang pemimpin dapat berpengaruh terhadap kinerja karyawan.

Adapun indikator menurut Rustam Efendi (2013) dalam Ajeng dan rini (2016) menyatakan bahwa indikator kepemimpinan adalah sebagai berikut :

1. Mampu mempengaruhi bawahan

2. Memberikan keteladanan kepada bawahan

3. Membangun suasana kerja dengan bawahan

4. Melakukan komunikasi dengan bawahan

\section{Stres Kerja}

Stres kerja adalah reaksi badan yang tidak menentu akibat suatu aksi. Reaksi badan sesorang tidaklah sama sehingga dampak stres lebih bersifat individual. Dampak stres kerja tidaklah selalu negatif ada juga yang berdampak positif ( Sentot Imam wahyono 2015). Menurut Mangkunegara ( dalam Dewi Margareta,2015) mengungkapkan bahwa stres adalah perasaan tertekan yang dialami karyawan dalam menghadapi pekerjaan. Pada kondisi stres yang tinggi karyawan mengalami ganggunan psikologi maupun fisik dalam menghadapi suatu permasalahan atau permasalahan yang berakibat merusak kinerja karyawan, namun pada tingkat tertentu dapat meningkatkan kinerja karyawan.

Indikator Stres Kerja yang di kemukakan oleh Hasibuan (2014:204) adalah sebagai berikut :

1. Beban kerja, diukur dari persepsi responden mengenai beban kerja yang dirasakan berlebihan.

2. Sikap pemimpin, diukur dari persepsi responden mengenai sikap pemimpin yang kurang adil dalam menberikan tugas.

3. Waktu kerja, diukur dari persepsi responden mengenai waktu kerja yang dirasakan berlebihan.

4. Konflik, diukur dari persepsi responden mengenai konflik antara karyawan dengan pimpinan.

5. Otoritas kerja, diukur dari persepsi responden mengenai otoritas kerja yang berhubungan dengan tanggung jawab. 


\section{Lingkungan Kerja}

Menurut Sedarmayati (2001:1) lingkungan kerja merupakan kseluruhan alat perkakas dan bahan yang dihadapi, lingkungan sekitarnya dimana seseorang bekerja, metode kerjanya, serta pengaturan kerjanya baik sebagai perseorangan maupun sebagai kelompok. Meskipun lingkungan kerja tidak melaksanakan proses produksi dalam suatu perusahaan,namun lingkungan kerja mempunyai pengaruh langsung terhadap para karyawan yang melaksanakan proses produksi tersebut.

\section{Kepemimpinan}

Memberikan rasa aman dan memungkinkan karyawan untuk dapat bekerja secara optimal.

Indikator lingkungan kerja menurut Sedarmayanti (2001:46) adalah sebagai berikut :

1. Penerangan

2. Suhu udara

3. Suara bising

\section{Penelitian Terdahulu}

Penelitian yang dilakukan Ajeng dan Rini (2016), yang membuktikan bahwa kepemimpinan, motivasi kerja dan disiplin kerja berpengaruh positif \& signifikan terhadap kinerja karyawan. Kemudian penelitian Ayu chandra Tri Buana Dewi (2016) serta penelitian oleh Anita Septiana (2018) yang menyatakan bahwa Kepemimpinan, stres kerja berpengaruh positif \& signifikan terhadap kinerja karyawan

Menurut Muchamad Abdul Kholil (2014) lingkungan kerja dan disiplin kerja berpengaruh positif \& signifikan terhadap kinerja karyawan. Menurut penelitian Risfatul Khotimah, Edward gagah, SE.MM (2017) dan Aldo Herlambang (2014) yang menyatakan bahwa kepemimpinan, stres kerja dan lingkungan kerja berpengaruh positif \& signifikan terhadap kinerja karyawan.

\section{Hipotesis}

$\mathrm{H}_{1} \quad$ : Kepemimpinan berpengaruh positif dan signifikan terhadap Kinerja Karyawan

$\mathrm{H}_{2}$ : Stres Kerja berpengaruh positif dan signifikan terhadap Kinerja Karyawan

$\mathrm{H}_{3}$ : Lingkungan Kerja berpengaruh positif dan signifikan terhadap Kinerja Karyawan

\section{METODOLOGI}

\section{Populasi, Sampel dan Teknik Sampling}

Populasi adalah wilayah genelarisasi yang terdiri atas obyek atau subyek yang mempunyai kualitas dan karaketeristik tertentu yang ditetapkan oleh peneliti untuk 
dipelajari dan kemudian ditarik kesimpulannya (Sugiyono, 2009:80). Adapun yang dijadikan sebagai populasi adalah karyawan PT.Samwon Busana Indonesia Semarang bagian produksi sewing yang berjumlah 330 karyawan.

Sampel adalah bagian dari jumlah dan karakteristik yang dimilki oleh populasi tersebut (Sugiyono, 2009:81). Sampel dalam penelitian ini berjumlah 77 responden. Teknik pengambilan sampel dalam penelitian ini menggunakan metode Purposive Sampling, yaitu teknik pengambilan sampel berdasarkan pertimbangan tertentu (Sugiyono, 2012:68). Kriteria dalam penentuan sampel lebih diutamakan untuk anggota populasi atau karyawan yang telah bekerja lebih dari 2 tahun.

\section{Jenis dan Sumber Data}

\section{a. Data Primer}

Menurut Sekaran (2011:242), Data primer adalah data yang diperoleh dari tangan pertama untuk analisis berikutnya untuk menemukan solusi atau masalah yang diteliti. Data primer ini berasal dari jawaban responden melalui kuesioner penelitian.

b. Data Sekunder

Menurut Sugiyono (2012: 137), Data sekunder adalah Sumber data yang tidak langsung memberikan data kepada pengumpul data, misalnya lewat orang lain atau lewat dokumen. Data ini perlu adanya pelengkap yang diperolah dari literature-literatur, jurnal terdahulu, data dokumen perusahaan yang berhubungan dengan penelitian.

\section{Metode Pengumpulan Data}

Untuk memperoleh data yang relevan objektif dan dapat dijadikan landasan dalam proses analisis, maka diperlukan pengumpulan data dengan metode:

a. Wawancara

Wawancara merupakan metode pengumpulan data dengan cara bertanya langsung (berkomunikasi langsung) dengan responden (Soeratno dan Arsyad, 2008:86). Dalam wawancara ini diadakan tanya jawab dengan bagian pimpinan (manajer produksi) mengenai data yang dibutuhkan.

b. Observasi

Observasi adalah cara pengumpulan data dengan cara melakukan pencatatan secara sistematis, secara cermat dan sistematik (Soeratno dan Arsyad, 2008:83). Dilakukan dengan pengamatan dan pencatatan secara langsung ke objek penelitian.

c. Metode Kuesioner

Kuesioner (angket) merupakan teknik pengumpulan data yang dilakukan dengan cara memberi seperangkat pertanyaan atau pernyataan tertulis kepada responden untuk dijawabnya (Sugiyono, 2013:137).

\section{Alat Analisis}

1. Uji Validitas

Menurut Sekaran (2006:248) dalam Sarjono dan Julianita (2011:35), validitas adalah bukti bahwa instrumen, teknik, atau proses yang digunakan untuk mengukur 
sebuah konsep benar-benar mengukur konsep yang dimaksudkan. Uji validitas bertujuan untuk mengukur valid tidaknya suatu item pertanyaan. Uji validitas merupakan ukuran yang menunjukkan sejauh mana kevalidan suatu instrumen penelitian.

2. Uji Reliabilitas

Menurut Sekaran (2006:40) dalam Sarjono dan Julianita (2011:35) menyatakan bahwa keandalan (reliability) suatu pengukuran menunjukkan sejauh mana pengukuran tersebut dilakukan tanpa bias (bebas kesalahan - error free). Dalam penelitian ini, teknik uji reliabilitas dengan menggunakan teknik Cronbach's Alpha $(\alpha)$. Suatu kuesioner dikatakan reliable jika nilai Cronbach's Alpha> 0,60 (Sarjono dan Julianita, 2011:45) dimana pengujian realibilitas ini menggunakan komputer program SPSS.

\section{Uji Asumsi Klasik}

a. Uji Multikolinieritas

Uji multikolinieritas bertujuan untuk menguji apakah model regresi ditemukan adanya korelasi atau hubungan yang signifikan antar variabel bebas. (Ghozali, 2011:105). Model regresi yang baik seharusnya tidak terjadi korelasi diantara variabel independen (variabel bebas). Untuk mendeteksi gejala multikolinearitas dapat dilihat dari nilai VIF (Variance Inflation Factor). Menurut Ghozali (2006:96), langkah untuk menganalisis asumsi multikolineritas yaitu :

- Jika nilai Tolerance $>$ dari 0,1 dan nilai VIF < dari 10 maka tidak ditemukan adanya multikolineritas.

- Jika nilai Tolerance < dari 0,1 dan nilai VIF > dari 10 maka ditemukan adanya multikolineritas.

b. Uji Heteroskedastisitas

Uji heteroskedastisitas bertujuan untuk menguji apakah dalam model regresi terjadi ketidaksamaan variance dari residual satu pengamatan yang pengamatan yang lain. Jika variance dari residual satu pengamatan ke pengamatan lain tetap, maka disebut Homoskedastisitas dan jika berbeda disebut Heteroskedastisitas. Model regresi yang baik adalah yang homokedastisitas atau tidak terjadi Heteroskedastisitas ( Ghozali, 2011:139). Salah satu cara untuk mendeteksi adanya heterokedastisitas adalah dengan metode uji glejser, dimana tidak terjadi heterokedastisitas, apabila nilai probabilitas lebih besar dari 0,05 maka dapat dipastikan model tersebut tidak terjadi heterokedastisitas begitu pula sebaliknya.

c. Uji Normalitas

Uji Normalitas bertujuan untuk menguji apakah dalam model regresi, kedua variabel ( bebas maupun terikat ) mempunyai distribusi normal atau setidaknya mendekati normal (Ghozali, 
2006:147). Jika data berdistribusi normal, maka uji hipotesis menggunakan statistic parametik, sedangkan jika data berdistribusi tidak normal maka digunakan uji hipotesis statsitik non parametik. Untuk menganalisis apakah residual berdistribusi normal atau tidaknya menggunakan 2 cara yaiutu, analisa grafik dan uji statistic.

\section{Analisis Regresi Berganda (Multiple Linear Regretion)}

Menurut Sekaran (2006: 299) dalam Sarjono dan Julianita (2011: 91) analisis regresi berganda dilakukan untuk menguji pengaruh stimultan dari beberapa variabel bebas terhadap satu variabel terikat yang berskala interval. Analisis ini digunakan untuk mengetahui bagaimana pengaruh antara variabel bebas atau variabel independen (X) terhadap variabel terikat atau variabel dependen (Y). Rumus Regresi Berganda adalah :

\section{$\mathbf{Y}=\mathbf{a}+\mathbf{b}_{1} \mathbf{X}_{1}+\mathbf{b}_{2} \mathbf{X}_{2}+\mathbf{b}_{3} \mathbf{X}_{3}+\mathbf{e}$}

\section{Uji F}

Uji F pada dasarnya menunjukkan apakah semua variabel independen atau bebas yang dimasukkan dalam model mempunyai pengaruh secara bersama-sama terhadap variabel dependen atau terikat (Ghozali, 2012).Atau untuk menguji apakah model regresi yang dibuat sudah tepat atau tidak. Adapun tahap pengujiannya adalah:

- Ho : Variabel-variabel bebas yaitu kepemimpinan, stres kerja, lingkungan kerja tidak berpengaruh yang signifikan terhadap variabel terikatnya yaitu kinerja karyawan.

- $\mathrm{H}_{\mathrm{a}} \quad$ : Variabel-variabel bebas yaitu kepemimpinan, stres kerja, lingkungan kerja berpengaruh yang signifikan terhadap variabel terikatnya yaitu kinerja karyawan.

Dasar pengambilan keputusannya (Ghozali,2012) adalah dengan menggunakan angka probabilitas signifikansi, yaitu:

a. Apabila probabilitas signifikansi > 0.05 , maka $\mathrm{H}_{0}$ diterima dan $\mathrm{H}_{\mathrm{a}}$ ditolak.

b. Apabila probabilitas signifikansi $<0.05$, maka $\mathrm{H}_{0}$ ditolak dan $\mathrm{H}_{\mathrm{a}}$ diterima.

\section{Uji Hipotesis Parsial (Uji t)}

Uji t digunakan untuk membuktikan hipotesis ada tidaknya pengaruh masing-masing variabel bebas secara individu terhadap variabel terikat. Uji t dilakukan dengan cara membandingkan nilai $t$ hitung dengan nilai $t$ tabel pada taraf signifikan $(\alpha) 0,05$ atau $5 \%$. Pengujian (uji t) secara parsial dengan membandingkan nilai thitung dengan nilai $\mathrm{t}$ tabel :

- Jika nilai $t_{\text {hitung }}>t_{\text {tabel }}$ maka Ho ditolak (Ha diterima) 
- Jika nilai $t_{\text {hitung }}<t_{\text {tabel }}$ maka Ho diterima

(Ha ditolak)

\section{Koefisien Determinasi $\left(\mathbf{R}^{2}\right)$}

Koefisien Determinasi $\left(\mathrm{R}^{2}\right)$ merupakan ukuran untuk mengetahui kesesuaian atau ketepatan antara variabel independen $\left(\mathrm{X}_{1}, \mathrm{X}_{2}\right.$ dan $\left.\mathrm{X}_{3}\right)$ dengan variabel dependen atau Y dalam suatu persamaan regresi. Dengan melihat koefisien determinasi, dapat diketahui seberapa besar pengaruh variable bebas (Disiplin Kerja, Lingkungan Kerja dan Kompensasi) terhadap variabel terikat (Kinerja Karyawan).

\section{HASIL DAN PEMBAHASAN}

\section{Uji Validitas}

Uji validitas dilakukan untuk menguji sejauhmana ketepatan alat ukur untuk menunjukkan tingkat kevalidan suatu instrumen. Instrumen dianggap valid apabila mampu mengukur apa yang diinginkan (Umar, 2003:80). Berdasarkan tabel dibawah ini menunjukkan bahwa pada pegujian validitas untuk masing- masing variabel disiplin kerja, lingkungan kerja dan Kompensasi dan kinerja karyawan hasil yang diperoleh menunjukkan bahwa tidak terdapat item pertanyaan yang tidak valid. Adapun hasil dari pengujian validitas ditetapkan antara lain :

\section{Uji Reliabilitas}

Suatu kuesioner dikatakan reliabel apabila jawaban yang diberikan olehresponden atas pernyataan yang diberikan dalam kuesioner konsisten atau stabil. Dalam penelitian ini, uji reliabilitas dilakukan dengan menggunakanprogram SPSSdengan Cronbach's Alpha >0,60. Suatu kuesioner dinyatakan reliable jika nilaiCronbach's Alpha > 0,60 (Sarjono danJulianita, 2011:45). Hasil uji reliabilitas dalam penelitian ini dapat dilihat pada table dibawah ini :

\section{Analisis Regresi Linier Berganda}

Analisis Regresi Linear Berganda dalam penelitian ini menggunakan alat bantu berupa program SPSS. Hasil Analisis Regresi Linear. Berdasarkan hasil regresi pada tabel diatas, dapat disimpulkan persamaan regresi dalam penelitian ini sebagai berikut :

$$
Y=0,322 X_{1}+0,402 X_{2}+0,273 X_{3}
$$

Berdasarkan hasil persamaan regresi diatas maka dapat disimpulkan bahwa :

a. Koefisien regresi untuk variabel kepemimpinan sebesar 0,322 bernilai positif, artinya semakin baik kepemimpinan yang diterapkan oleh perusahaan maka akan semakin meningkat kinerja karyawan 
b. Koefisien regresi untuk variabel stres kerja sebesar 0,402 bernilai positif, artinya semakin tinggi tingkat stres kerja yang dialami karyawan maka akan semakin meningkat kinerja karyawan.

c. Koefisien regresi untuk variabel lingkungan kerja sebesar 0,273 bernilai positif, artinya semakin baik lingkungan kerja yang diberikan oleh perusahaan maka akan semakin meningkat kinerja karyawan.

\section{Uji t}

Uji t dimaksudkan untuk mengetahui sebrapa jauh satu variabel independen (kepemimpinan, stres kerja dan lingkungan kerja) secara individual dapat menerangkan variabel dependen (kinerja karyawan). Hasil uji t pada penelitian ini dapat dilihat pada tabel dibawah ini :

\section{a. Variabel Kepemimpinan}

Berdasarkan hasil pengujian, diperoleh nilai $t_{\text {hitung }}$ antara kepemimpinan $\left(\mathrm{X}_{1}\right)$ terhadap kinerja karyawan $(\mathrm{Y})$ sebesar 4,285 > nilai $\mathrm{t}_{\text {tabel }}$ yaitu 1,665 dan nilai signifikansi sebesar $0,040<$ taraf signifikasi $a=5 \%(0,05)$. Hal ini berarti bahwa terdapat pengaruh yang positif dan siginfikan antara kepemimpinan $\left(\mathrm{X}_{1}\right)$ terhadap kinerja karyawan $(\mathrm{Y})$. sehingga hipotesis pertama diterima.

\section{b. Variabel Stres Kerja}

Berdasarkan hasil pengujian, diperoleh nilai thitung antara stres kerja $\left(\mathrm{X}_{2}\right)$ terhadap kinerja karyawan $(\mathrm{Y})$ sebesar 4,350 > nilai tabel yaitu 1,665 dan nilai signifikansi sebesar $0,000<$ taraf signifikasi $a=5 \%(0,05)$. Hal ini berarti bahwa terdapat pengaruh yang positif dan siginfikan antara stres kerja $\left(\mathrm{X}_{2}\right)$ terhadap kinerja karyawan

(Y) sehingga hipotesis kedua diterima.

\section{c. Variabel Lingkungan Kerja}

Berdasarkan hasil pengujian, diperoleh nilai thitung antara kompensasi $\left(\mathrm{X}_{3}\right)$ terhadap kinerja karyawan (Y) sebesar 2,565 > nilai $t_{\text {tabel }}$ yaitu 1,670 dan nilai signifikansi sebesar $0,013<$ taraf signifikasi $a=5 \%(0,05)$. Hal ini berarti bahwa terdapat pengaruh yang positif dan siginfikan antara kompensasi $\left(\mathrm{X}_{3}\right)$ terhadap kinerja karyawan (Y). sehingga hipotesis ketiga diterima.

\section{Uji F}

Hasil dari analisis deskriptif terhadap dari uji $\mathrm{F}$ diatas didapat nilai $\mathrm{F}$ hitung sebesar 134,546 dengan signifikasi 0,000. Karena probabilitas jauh lebih kecil dari 0,05 maka model regresi dapat dikatakan untuk memprediksi kinerja atau dapat dikatakan bahwa kepemimpinan, stres kerja dan lingkungan kerja berpengaruh terhadap kinerja karyawan. 
Dari hasil yang diperoleh maka dapat dilihat pada table F distribusi yang menghasilkan $\mathrm{F}$ tabel dari $(4 ; 77)$ adalah 2,50 . karena F hitung $(134,546)>$ F table $(2,50)$, maka Ho ditolak dan Ha diterima. Jadi dapat disimpulkan bahwa model regresinya layak digunakan untuk peramalan.

\section{Pembahasan}

Berdasarkan hasil dari penelitian yang dilakukan terhadap 77 orang responden, maka dapat diketahui bagaimana tanggapan para responden terhadap variabel-variabel (pernyataan-pernyataan) yang diajukan dalam kuesioner. Tanggapan responden tersebut dijelaskan dalam pembahasan berikut :

\section{Pengaruh Kepemimpinan terhadap Kinerja Karyawan}

Berdasarkan melalui hasil perhitungan yang telah dilakukan maka diperoleh nilai $\mathrm{t}_{\text {hitung }}$ variabel kepemimpinan sebesar 4,285 dengan nilai signifikansi sebesar 0,000. Nilai signifikansi ini lebih kecil dari nilai batas signifikansi, yaitu sebesar 0,05. Artinya Semakin baik kepemimpinan maka kinerja karyawan akan semakin meningkat. Seperti faktor pimpinan dapat menyelesaikan masalah dalam pekerjaan di area produksi, pimpinan dapat memberikan contoh teladan yang baik, pimpinan bisa membangun susana kerja yang kondusif, pimpinan dapat menjalin komunikasi dengan baik kepada bawahan. Hal tersebut mengindikasikan bahwa karyawan PT.Samwon Busana Indonesia Semarang memiliki penilaian yang baik terhadap kepemimpinan yang ada selama ini.

Berdasarkan hasil pengujian hipotesis menunjukkan bahwa Kepemimpinan berpengaruh positif dan signifikan terhadap Kinerja Karyawan. Semakin baik arahan yang dilakukan pemimpin terhadap karyawannya, maka semakin tinggi juga tingkat produktivitas kinerja karyawan. Hasil penelitian yang dilakukan oleh Ajeng dan Rini (2016) serta didukung penelitian yang dilakukan oleh Risfatul Khotimah Edward Gagah, SE.MM (2017) yang diperoleh hasil Kepemimpinan berpengaruh positif dan signifikan terhadap Kinerja Karyawan.

\section{Pengaruh Stres Kerja terhadap Kinerja Karyawan}

Berdasarkan melalui hasil perhitungan yang telah dilakukan maka diperoleh nilai

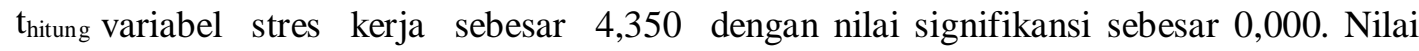
signifikansi ini lebih kecil dari nilai batas signifikansi, yaitu sebesar 0,05. Artinya dengan tingkat stres yang tinggi terhadap kinerja karyawan seperti beban kerja yang diberikan perusahan terlalu tinggi, sikap pemimpin saya kurang adil dalam memberikan tugas, jam kerja yang lebih dari kontrak kerja, hubungan karyawan antar karyawan kurang 
baik dan sistem otoritas kerja yang tinggi membuat tertekan dalam bekerja. Hal semacam ini mengindikasikan bahwa karyawan PT. Samwon Busana Indonesia Semarang memiliki penilaian yang baik terhadap stres kerja yang ada selama ini. Hal tersebut membuat karyawan PT.Samwon Busana Indonesia Semarang semakin berusaha agar bisa menyelesaikan pekerjaan sesuai target yang telah ditetapkan oleh perusahaan.

Berdasarkan hasil pengujian hipotesis menunjukkan bahwa stres kerja berpengaruh positif dan signifikan terhadap Kinerja Karyawan. Bahwa apabila semakin tinggi tingkat stres kerja maka perusahaan maka akan semakin memotivasi para karyawan untuk meningkatkan hasil kinerjanya. Hasil penelitian ini didukung penelitian yang dilakukan oleh Ayu Candra Tri Bhuana Dewi (2016) serta didukung penelitian yang dilakukan oleh Anita Septiana Sri Harini dan Sudarijati (2018) yang diperoleh hasil Stres Kerja berpengaruh positif dan signifikan terhadap Kinerja Karyawan.

\section{Pengaruh Lingkungan Kerja terhadap Kinerja Karyawan}

Berdasarkan melalui hasil perhitungan yang telah dilakukan maka diperoleh nilai

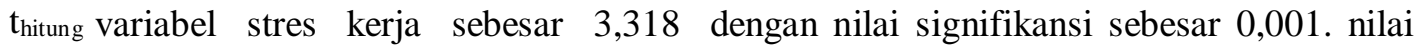
signifikansi ini lebih kecil dari nilai batas signifikansi, yaitu sebesar 0,05 yang artinya bahwa lingkungan kerja berpengaruh positif dan signifikan terhadap kinerja karyawan. Seperti faktor penerangan di ruang kerja yang baik, sirkulasi udara yang yang baik, area kerja yang sangat bising, bangunan yang cukup luas ,fasilitas kerja dan keamanan kerja yang memadai, hubungan antar karyawan yang baik.Hal semacam ini mengindikasikan bahwa karyawan PT. Samwon Busana Indonesia Semarang memiliki penilaian yang baik terhadap lingkungan kerja yang ada selama ini. Hal tersebut membuat karyawan PT.Samwon Busana Indonesia Semarang semakin nyaman dalam bekerja dan karyawan bisa menyelesaikan pekerjaan sesuai target yang telah ditetapkan oleh perusahaan maka kinerja karyawan akan naik.

Berdasarkan hasil pengujian hipotesis menunjukkan bahwa Lingkungan Kerja berpengaruh positif dan signifikan terhadap Kinerja Karyawan. Semakin mendukung sarana dan prasarana kerja maka akan semakin mendukung pula kinerja para karyawan. Hasil ini didukung penelitian yang dilakukan oleh Aldo Herlambang Gardjito, Mochammad Al Musadieq (2014) serta penelitian yang dilakukan oleh M. Abdul Kholil, Marzolina Taufiqurahman (2014) yang diperoleh hasil Lingkungan Kerja berpengaruh positif dan signifikan terhadap Kinerja Karyawan. 


\section{PENUTUP}

\section{Simpulan}

Berdasarkan penjelasan dan uraian

sebelumnya maka dapat disimpulkan sebagai berikut :

1. Kepemimpinan berpengaruh positif dan signifikan terhadap kinerja karyawan pada PT.Samwon Busana Indonesia Semarang.

2. Stres kerja berpengaruh positif dan signifikan terhadap kinerja karyawan pada PT.Samwon Busana Indonesia Semarang.

3. Lingkungan kerja berpengaruh positif dan signifikan terhadap kinerja karyawan pada PT.Samwon Busana Indonesia Semarang.

\section{Saran}

1. responden mengenai variabel kepemimpinan diketahui bahwa Indikator "pimpinan memberikan teladan yang tidak baik dalam bekerja" mendapatkan respon tidak setuju paling banyak. Oleh karena itu disarankan agar pimpinan bisa memberikan contoh membangun suasana kerja nyaman dan yang kondusif agar meningkatkan semangat para karyawan. Selain itu, pimpinan harus memperhatikan, mengarahkan karyawan agar bekerja lebih baik, membantu menangani masalah.memberikan dukungan, mengevaluasi kinerja karyawan agar kinerja karyawan semakin meningkat.

2. Hasil dari analisis deskriptif terhadap responden mengenai variabel stres kerja, diketahui bahwa indikator "sikap pemimpin saya adil dalam memberikan tugas" mendapatkan respon tidak setuju paling banyak. Karena kenyataan yang ada dilapangan apabila pimpinan tidak memperlakukan karyawan secara adil maka akan menimbulkan masalah. oleh karena itu disarankan agar pimpinan perusahaan harus bersikap adil dalam memberikan tugas kepada karyawan antar karyawan agar kinerja mereka semakin meningkat.

3. Hasil dari analisis deskriptif terhadap responden mengenai variabel ligkungan kerja diketahui bahwa indikator "sirkulasi udara diruang kerja sudah baik" mendapatkan respon tidak setuju paling banyak. artinya sirkulasi udara di area produksi dirasakan belum cukup membuat nyaman karyawan dalam bekerja. oleh karena itu disarankan agar perusahaan dapat memberikan sirkulasi udara yang lebih baik lagi seperti memberikan ventilasi yang memadai agar karyawan bekerja menjadi lebih nyaman dan kinerja karyawan akan meningkat.

\section{DAFTAR PUSTAKA}

Astianto, A. (2014). Pengaruh Stres Kerja dan Beban Kerja Terhadap Kinerja Karyawan PDAM Surabaya. Jurnal Ilmu \& Riset Manajemen Vol. 3 No. 7 , https://ejournal.stiesia.ac.id/jirm/article/ download/572/539. 
Basri, R. (2005). Perfomance Appraisal. JAkarta: PT. Raja Grafindo Persada.

Dewi, A. B., \& Sintaasih, D. K. (2016). Pengaruh Stres Kerja dan Komitmen Orgnisasional Terhadap Kinerja Karywan pada PT. Bangun Bali Uatama Denpasar. Volume 6 no 2.

Ferdinand, A. (2013). Metode Penelitian Manajemen. Semarang: Badan Penerbit Undip.

Gardjito, A. H., \& Musadieq, M. A. (2014). Analisis Pengaruh Motivasi Kerja Dan Lingkungan Kerja Terhadap Kinerja Karyawan (PT.Karmand Mitra Andalan Bagian Produksi). Jurnal Administrasi Bisnis Volume 13 no. 1

Ghozali, I. (2012). Aplikasi Analisis Multivariate dengan Program IBM SPSS 20. Semarang: Badan Penerbit Universitas Diponegoro.

Hasibuan, M. S. (2008). Manajemen Sumber Daya Manusia (Edisi Revisi). Jakarta: PT. Bumi Aksara.

Hasibuan, M. S. (2009). Manajemen Dasar, Pengertian, Dan Masalah. Jakarta: PT. Bumi Aksara.

Hasibuan, M. S. (2014). Manajemen Sumber Daya Manusia (Edisi Revisi). Jakarta: Bumi Aksara.

Manajemen Sumber Daya Manusia. (2006). In Anwar Prabu Mangkunegara 2009, Perencanaan Dan Pengembangan SDM. Bandung: Aditama, PT.Refika.

Mangkunegara, A. P. (2000). MAnajemen Sumber Daya Manusia. Bandung: PT. Remaja RosdaKarya.

Munandar, A. S. (2008). Psikologi Industri dan Organisasi. Jakarta: UI-press.

Nuraini , T. 2013. Manajemen Sumber Daya Manusia. Jakarta. Rineka Cipta. Jurnal FEKON vol. 1 no. 2 oktober 2014

Parmin. (2016). Analisis Pengaruh Kepemimpinan, Motivasi dan Stres Kerja Terhadap Kinerja Karyawan (CV.Dian Prima Kebumen). Jurnal Fokus Bisnis Volume, Nomer 02 Desember.

Prameswari, A. A., \& Nugraheni, R. (2016). Analisis Pengaruh Kepemimpinan, Motivasi Kerja dan Disiplin Kerja Terhadap Kinerj Karyawan. Diponegoro Journal Of Management, volume 5 Nomor 1, Halaman 1-12.

Qodarini, F. L., \& Nugraheni, R. (2015). Analisis Pengaruh, Disiplin Kerja, Kepuasan Kerja Dan Gaya Kepemimpinan Terhadap Kinerja Karyawan (Studi Pada Karyawan Bagian Produksi PT.Nyonya Meneer Semarang). Diponegoro Journal Of Management, Volume Nomor 3.

Rivai, V. (2005). Manajemen Sumber Daya Manusia untuk Perusahaan. Jakarta: PT. Raja Grafindo Persada.

Robbins, S. P. (2013). Perilaku Organisasi. Jakarta: Index.

Robbins, S. P., \& Judge, T. A. (2008). Perilaku Organisasi Edisi ke-12. Jakarta: Salemba Empat. 
Sarjono, Haryadi Dan Winda Julianita. 2011. SPSS vs LISREL: Sebuah Pengantar, Aplikasi Untuk riset. Jakarta : Salemba Empat

Sedarmayanti.2001. (n.d.). In S. D. Kerja:, Suatu Tinjauan Dari Aspek . Septiana, A., Harini, S., \& Sudarijati. (Volume 8 Nomor 1 2018). Pengaruh Stres Kerja dan Kepemimpinan Terhadap Kinerja Karyawan. Jurnal Sosial Humaniora.

Soekarso, Sosro, A., Putong, I., \& Hidayat, C. (2010). Teori Kepemimpinan. Jakarta: Mitra Wacana Media.

Sugiono. (2010). Metode Penelitian Pendidikan Pendekatan Kuantitatif, kualitatif, dan R\&D. Bandung: Penerbit Alfabeta.

Sugiono. (2014). Metode Penelitian Kuantitatif, Kualitatif, dan R\&D. Bandung: Penerbit Alfabeta.

Susilo, I. T., \& Anomsari, A. (n.d.). Pengaruh Kepemimpinan , Motivasi, Lingkungan Kerja dan disiplin Kerja Terhadap Kinerja karyawan Bagian Produksi PT. Arindo Garmentama Semarang.

Susitianingrum, N., Djoko, H., \& Dewi, R. S. (2015). Pengaruh Lingkungan Kerja, Motivasi Kerja dan Disiplin Kerja Terhadap Kinerja Karyawan Bagian Produksi PT. Njonja Meneer Semarang. Diponegoro Journal Of Social And Political Of Science, 1-11.

Thoha, M. (2007). MAnajemen Dalam Kepemimpinan. Jakarta: PT. Raja Grafindo.

Umar, H. (2001). Strategic Management in Action. Jakarta: Gramedia Pustaka Utama 